\title{
Perfil bioquímico sérico de bezerros senepol nos primeiros 120 dias de idade
}

\section{Serum biochemical profile in senepol calves at the first 120 days of age}

\author{
Jéssica Lawanne Delfino; ; Vinicius de Morais Barbosa²; Cristóvão Costa Gondim²; \\ Patricia Magalhães de Oliveira ${ }^{3 *}$; Nayara Resende Nasciutti ${ }^{3}$; \\ Raphael Soares de Barros Ramos Oliveira'; Suzana Akemi Tsuruta ${ }^{4}$; \\ Antonio Vicente Mundim ${ }^{5}$ João Paulo Elsen Saut ${ }^{5}$
}

\section{Resumo}

\begin{abstract}
A bioquímica sérica permite estabelecer valores de referência utilizados na avaliação clínica e metabólica de bezerros, reduzindo as perdas na criação bovina. Neste contexto, objetivou-se avaliar o perfil bioquímico sérico e a influência do fator etário em bezerros da raça Senepol, do nascimento até 120 dias de idade. $\mathrm{O}$ experimento foi realizado no município de Uberlândia-MG, Brasil, em quatro momentos após o nascimento $\left(0-15^{\circ}, 30^{\circ}, 60^{\circ}\right.$ e $120^{\circ}$ dia de vida). As amostras de sangue foram obtidas por venopunção da jugular para determinação das concentrações séricas de proteínas totais, albumina, globulina, triglicerídeos, colesterol, AST, GGT, FA, cálcio, fósforo, magnésio, creatinina e uréia. O colesterol manteve-se abaixo ou nos valores mínimos de referência em todos os momentos. Os animais aos 30 dias apresentaram os valores mais baixos do proteinograma, minerais e triglicerídeos que se normalizaram aos 60 dias de vida, exceto a albumina que apresentou recuperação mais lenta. Concluiuse que há influência da faixa etária no comportamento dos constituintes bioquímicos analisados e que há diferenças quando comparados a outras raças.
\end{abstract}

Palavras-chave: Bezerros, bioquímica sérica, colesterol, Bos taurus

\begin{abstract}
The serum biochemical values allow to establish reference used in metabolic and clinical evaluations of calves, reducing losses in cattle breeding. The aim of this study was to evaluate the influence of age on serum biochemical profile in Senepol calves, at the first 120 days of age. The experiment was conducted in the city of Uberlândia, Minas Gerais, Brazil, in four periods after birth $(0-15,30,60$ and 120 days of age). Blood samples were obtained by jugular venipuncture for determination of serum total protein, albumin, globulin, triglycerides, cholesterol, AST, GGT, FA, calcium, phosphorus, magnesium, creatinine and urea. Cholesterol remained at minimum reference values or below throughout the experiment. Animals at 30 days showed the lowest values of protein concentrations, minerals and triglycerides that normalized up to 60 days of life, except to albumin that slower recovery was showed. Our data showed that the serum biochemical profile in Senepol is influenced by age up to 120 days of age; moreover there are differences with other breeds.
\end{abstract}

Key words: Calves, serum biochemical, cholesterol, Bos tauros

1 Médicos Veterinários autônomos, Uberlândia, MG. E-mail: jessicadelfino@hotmail.com; raphael_vet@hotmail.com

2 Discentes do Curso de Medicina Veterinária da Faculdade de Medicina Veterinária da Universidade Federal de Uberlândia, FAMEV/UFU, Uberlândia, MG. E-mail: vinicius.barbosa6@hotmail.com; cristovaogondim@yahoo.com.br

3 Discentes do Programa de Pós-graduação em Ciências Veterinárias, UFU, Uberlândia, MG. E-mail: pathymaga@hotmail.com; nayaranasciutti@yahoo.com.br

4 Discente do Programa de Pós-graduação em Ciências Veterinárias, Universidade Federal de Goiás, UFG, Goiânia, GO. E-mail: suzanaakemi@yahoo.com.br

5 Profs. Adjuntos III da FAMEV/UFU, Uberlândia, MG. E-mail: avmundim@demea.ufu.br; jpsaut@famev.ufu.br

* Autor para correspondência 


\section{Introdução}

A consolidação do Brasil no mercado mundial de carne bovina e o consequente aumento da competitividade com outros mercados têm requerido que a pecuária de corte oferte um produto de qualidade e com regularidade. Esta demanda juntamente com a necessidade de se aumentar a eficiência do setor têm sido os grandes motores do processo de reestruturação em curso na cadeia produtiva da carne bovina (EUCLIDES FILHO; FIGUEREDO; EUCLIDES, 2003).

A pecuária brasileira tem vivenciado um aumento na introdução de raças taurinas (adaptadas e não adaptadas) e no uso de cruzamentos industriais, visando à melhoria da produtividade, da qualidade da carne e da eficiência dos sistemas de produção (RIBEIRO; ALENCAR; OLIVEIRA, 2008). O cruzamento industrial envolvendo raças europeias adaptadas, como a raça Senepol, pode se constituir em importante componente de sistemas de produção de bovinos de corte para as condições do Brasil Central Pecuário (EUCLIDES FILHO et al., 2004).

A raça Senepol foi formada a partir de duas raças taurinas, a Red Poll (de origem britânica) e a N'Dama (origem africana) e introduzida recentemente no Brasil. Além das características de produtividade e qualidade da carne, a raça Senepol apresenta um tipo diferente de pelagem constituída por pêlos curtos, lisos e brilhantes, denominada "slick hair", e que esta está relacionada com a maior tolerância ao calor (OLSON et al., 2003). A adaptabilidade desta raça ao clima tropical é produto da contribuição da raça N'Dama durante sua formação, que de acordo com Mattioli et al. (2000), possui uma resistência natural a infestação por carrapatos, tripanosomíase e às infecções por nematódeos gastrintestinais.

O perfil metabólico em animais de produção auxilia na avaliação de rebanhos com diferentes índices produtivos (PEIXOTO et al., 2010) e na literatura consultada ainda há pouca informação relacionada à raça Senepol. Segundo Caldeira, Belo e Santos (2007), o sangue é o fluido mais utilizado para determinação da concentração de indicadores do estado nutricional ou metabólico. Os constituintes sanguíneos têm variações fisiológicas e patológicas que disponibilizam informações de grande valor para o diagnóstico e prognóstico de doenças, principalmente, as metabólicas, responsáveis por quedas de produção (FERREIRA NETO; VIANA; MAGALHÃES, 1982).

Altos índices de mortalidade de bezerros durante a cria constituem uma das principais perdas na atividade pecuária. Os conhecimentos das variáveis fisiológicas no aspecto clínico laboratorial contribuem para a redução dessa mortalidade e permitem maior eficiência no atendimento clínico (BENESI, 1993). Entretanto, para correta interpretação do perfil metabólico é necessário valores de referência apropriados para cada população (GONZÁLEZ; SCHEFFER, 2002).

Sabendo-se da importância da bioquímica sérica como ferramenta de diagnóstico e da escassez de informações sobre perfil sérico de bezerros da raça Senepol em crescimento, delineou-se esta pesquisa com o objetivo de avaliar o perfil bioquímico sérico e a influência do fator etário em bezerros da raça Senepol nos primeiros 120 dias de idade.

\section{Material e Métodos}

O experimento foi realizado em duas fazendas da região de Uberlândia, localizada na porção sudoeste do Estado de Minas Gerais - Brasil. O clima local na região é classificado como Aw (KÖPPEN, 1948), com temperatura média anual de $22,3^{\circ} \mathrm{C}$, umidade relativa do ar em torno de $71 \%$ e precipitação pluviométrica de aproximadamente $1500 \mathrm{~mm}$ anuais.

As coletas de sangue foram feitas em bezerros da raça Senepol, de ambos os sexos, no período de dezembro de 2010 a março de 2011. Estas coletas foram realizadas em quatro momentos, sendo eles do nascimento até o $15^{\circ}$ dia (10 animais), $30^{\circ}$ dia (22 animais), $60^{\circ}$ dia (23 animais) e $120^{\circ}$ dia de vida 
(14 animais). As coletas não foram feitas sempre dos mesmos animais e bezerros que não passaram no exame clínico proposto foram eliminados do projeto e não utilizados em nenhum outro momento. Todos os partos foram eutócicos e provenientes de inseminação artificial, transferência de embrião e fecundação in vitro.

Os partos foram assistidos e certificou-se que todos os animais receberam colostro suficiente logo após o nascimento. Estes bezerros permaneceram durante os 120 dias do experimento em sistema extensivo e na presença da mãe. Os piquetes eram formados de capins do gênero Brachiaria com água e sal mineral ad libitum. Além disso, era fornecido concentrado com $18 \%$ de proteína a partir dos 45 60 dias. A vermifugação a base de ivermectina, via subcutânea, foi realizada em todos os bezerros aos 30 dias de idade. Aos quatro meses de vida todos os animais foram vacinados com vacina comercial polivalente para clostridioses.

Após a realização do exame clínico (FEITOSA, 2008), separaram-se os animais enfermos e apenas os saudáveis participaram das coletas. As amostras de sangue foram coletadas com sistema vacutainer em tubos sem anticoagulante e, padronizou-se realizar sempre no período da manhã, condicionadas, refrigeradas e transportadas ao Laboratório de Análises Clínicas do Hospital Veterinário da Universidade Federal de Uberlândia. No laboratório, as amostras foram centrifugadas a 5000 rotações por minuto, durante cinco minutos, em centrífuga Excelsa Baby (centrífuga marca FANEM, modelo 206). Após, o soro era separado em alíquotas nos microtubos tipo eppendorf e armazenados a menos $20^{\circ} \mathrm{C}$ até o momento das análises, de no máximo cinco dias após a coleta. $\mathrm{O}$ perfil bioquímico foi realizado em analisador automático multicanal ChemWell, previamente calibrado (Calibra $\mathrm{H}$ ) e aferido com soro controle (Qualitrol 1) à temperatura de $37^{\circ} \mathrm{C}$.
Os parâmetros analisados e os métodos utilizados para determinação do metabolismo proteico foram: concentração sérica da proteína total (biureto), albumina (verde bromocresol) e concentração de globulina (proteína total menos albumina) determinada por (COLES, 1984), além da relação albumina/globulina. No metabolismo energético foram determinadas as concentrações de triglicerídeos e colesterol pelo método enzimático Trinder.

As enzimas determinadas com a respectiva metodologia foram: alanina aminotransferase (ALT) e aspartato aminotransferase (AST) - método cinético UV-IFCC; gama glutamiltransferase (GGT) - método Szasz modificado; fosfatase alcalina (FA) - método cinético optimizado- Bowers e Mc Comb modificado. A creatinina foi determinada pelo método de Picrato alcalino e a uréia pelo enzimático cinético UV. Nos minerais determinaram-se as concentrações séricas do cálcio (cresolftaleína complexona - CPC), fósforo (Daly e Ertingshausen modificado), magnésio (Magon sulfonado) e cálculo da relação cálcio/fósforo.

Para análise estatística, utilizou-se o programa Minitab - versão 15 (Minitab Inc, Pennsylvania, USA) e os dados foram apresentados através da sua média aritmética e desvio-padrão, de acordo com Vieira (2003). As variáveis, inicialmente, foram submetidas ao Teste de Kolmogorov-Smirnov para verificar se os dados apresentavam ou não distribuição paramétrica.

As variáveis com distribuição paramétrica (proteínas totais, globulina, albumina, relação albumina/globulina, triglicerídeos, colesterol, cálcio, fósforo, magnésio, relação cálcio/fósforo, AST, FA, uréia e creatinina) foram submetidas à análise de variância (ANOVA paramétrica) e pós-teste de Tukey's ( $\mathrm{p} \leq 0,05)$. As variáveis com distribuição não-paramétrica (GGT) foram analisadas pelo teste de Kruskall-Wallis (Anova não-paramétrica) e pósteste de Comparação Múltipla de Dunn's $(\mathrm{p} \leq 0,05)$. 


\section{Resultados e Discussão}

Os constituintes do proteinograma sérico apresentaram variações significativas em relação ao desenvolvimento etário, conforme descrito na Tabela 1. Observou-se queda na concentração das proteínas totais dos primeiros 15 dias de vida $(7,43$ $\pm 0,62 \mathrm{~g} / \mathrm{dL})$ até os 30 dias $(4,59 \pm 0,80 \mathrm{~g} / \mathrm{dL})$. De acordo com Kaneko, Harvey e Bruss (2008) os valores de referência para bovinos são de 6,74 a $7,46 \mathrm{~g} / \mathrm{dL}$.

Tabela 1. Valores dos constituintes do proteinograma sérico de bezerros da raça Senepol, do nascimento até os 120 dias de idade.

\begin{tabular}{ccccc}
\hline DIAS & $\begin{array}{c}\text { Proteínas totais } \\
(\mathrm{g} / \mathrm{dL})\end{array}$ & $\begin{array}{c}\text { Globulina } \\
(\mathrm{g} / \mathrm{dL})\end{array}$ & $\begin{array}{c}\text { Albumina } \\
(\mathrm{g} / \mathrm{dL})\end{array}$ & Relação A/G \\
\cline { 2 - 5 } $0-\mid 15$ & $7,43 \pm 0,62^{\mathrm{a}}$ & $4,44 \pm 0,73^{\mathrm{a}}$ & $2,99 \pm 0,26^{\mathrm{a}}$ & $0,69 \pm 0,16^{\mathrm{a}}$ \\
30 & $4,59 \pm 0,80^{\mathrm{b}}$ & $2,83 \pm 0,71^{\mathrm{b}}$ & $1,75 \pm 0,30^{\mathrm{b}}$ & $0,65 \pm 0,17^{\mathrm{a}}$ \\
60 & $6,69 \pm 1,04^{\mathrm{a}}$ & $4,71 \pm 1,00^{\mathrm{a}}$ & $1,97 \pm 0,34^{\mathrm{b}}$ & $0,43 \pm 0,12^{\mathrm{b}}$ \\
120 & $9,63 \pm 0,90^{\mathrm{c}}$ & $6,99 \pm 1,09^{\mathrm{c}}$ & $2,64 \pm 0,22^{\mathrm{c}}$ & $0,38 \pm 0,07^{\mathrm{b}}$ \\
Referência* & $6,74 \mathrm{a} 7,46$ & $2,62 \mathrm{a} 4,04$ & $2,6 \mathrm{a} 3,7$ & 0,6 a 0,9 \\
\hline
\end{tabular}

* Kaneko, Harvey e Bruss (2008). Letras diferentes nas colunas diferem estatisticamente $(\mathrm{p}<0,05)$. Relação A/G- relação albumina/ globulina.

Fonte: Elaboração dos autores.

Os valores encontrados de proteínas totais nos primeiros 15 dias de vida são reflexo da concentração sérica de globulinas $(4,44 \pm 0,73 \mathrm{~g} / \mathrm{dL})$. Estes valores de globulinas devem-se, provavelmente, à absorção adequada de imunoglobulinas através da ingestão do colostro, a qual foi assistida em todos os animais, e posteriormente, devido à atividade catabólica e síntese endógena de imunoglobulinas (PAULETTI et al., 2003). Estes valores estiveram maiores que o descrito por pesquisadores brasileiros (COSTA et al., 2008), em bezerros da raça Nelore e Limousin, entre 24 e 36 horas, de 7,19 $\pm 0,75 \mathrm{~g} /$ dl e $6,32 \pm 0,98 \mathrm{~g} / \mathrm{dl}$, respectivamente, e Rocha et al. (2010), em bezerros Canchim-Nelore, aos 7 e 15 dias, filhos de vacas primíparas $(7,0 \pm 0,35 ; 7,0 \pm$ $0,16 \mathrm{~g} / \mathrm{dl})$ e pluríparas $(6,71 \pm 0,07 ; 7,4 \pm 0,22 \mathrm{~g} / \mathrm{dl})$, respectivamente.

A queda observada nas concentrações séricas de proteína, albumina e globulina aos 30 dias de vida, concordam com outras raças em condições semelhantes de manejo (COSTA et al., 2008), exceto em relação à albumina. No entanto, os valores já estavam dentro dos valores de referência (KANEKO; HARVEY; BRUSS, 2008) no $60^{\circ}$ dia de vida, excetuando-se novamente a albumina, que apenas se normalizou no último momento avaliado, aos 120 dias de vida $(2,64 \pm 0,22 \mathrm{~g} / \mathrm{dl})$. De acordo com Payne e Payne (1987) a detecção de variações séricas de albumina necessita de um período mínimo de um mês, devido à baixa velocidade de síntese dessa proteína.

Este aumento de albumina pode ter sido auxiliado pelo acréscimo gradativo na ingestão de volumoso e concentrados, além do tratamento antiparasitário. Os resultados condizem com Moraes (2011); Costa et al. (2008), para 60 e 120 dias de vida, respectivamente, de 2,5 $\pm 0,4 \mathrm{~g} / \mathrm{dl}$ a $3,0 \pm 0,6 \mathrm{~g} / \mathrm{dl} \mathrm{e}$ de $3,59 \pm 0,36 \mathrm{~g} / \mathrm{dl}$ a $3,60 \pm 0,31 \mathrm{~g} / \mathrm{dl}$ para bezerros Nelore.

O aumento de globulinas séricas, observado no $120^{\circ}$ dia de vida, pode relacionar-se ao período pósvacinação, que foi realizado nessa fase nas fazendas utilizadas com vacina polivalente comercial contra clostridioses. Segundo Pike (1967) a administração parenteral de antígenos, em hospedeiro saudável, resulta na produção de imunoglobulinas. Moraes (2011) descreveu esse período pós-vacinação em bezerros Holandeses aos 270 dias, com resultados 
de proteína total $(9,5 \pm 13,7 \mathrm{~g} / \mathrm{dl})$ e globulinas $(7,0$ $\pm 13,9 \mathrm{~g} / \mathrm{dl})$ semelhantes aos encontrados neste experimento (Tabela 1$)$.

A relação $\mathrm{A} / \mathrm{G}$ (Tabela 1) apresentou queda significativa do nascimento até 120 dias de vida e os resultados apresentados nos dois últimos momentos ficaram abaixo dos valores de referência (KANEKO; HARVEY; BRUSS, 2008), os quais também diferiram de Costa et al. (2008) que encontraram essa relação baixa apenas nos primeiros 15 dias em bezerros Nelore e nas primeiras 36 horas em bezerros Limousin. Leal et al. (2003) também relataram que até os 30 dias de idade as relações ficaram baixas, com valores menores entre 8 e 48 horas de vida de bezerros Holandeses, um declínio decorrente do aumento das globulinas séricas em virtude da mamada do colostro rico em gamaglobulinas (SRIDHAR; KUMAR, 1988).

Nos estudos dos parâmetros bioquímicos sanguíneos, a atividade das enzimas AST, ALT, GGT e FA são considerados biomarcadores sanguíneos de grande valor na avaliação de distúrbios metabólicos, funcionamento hepático, alterações ósseas e desequilíbrio na relação cálcio/fósforo (MUNDIM et al., 2007).

Os valores de GGT nos primeiros 15 dias de vida foram superiores aos outros momentos avaliados (Tabela 2). Estes valores eram esperados e concordaram com Gasparelli (2007) e Benesi et al. (2003), pois as altas concentrações de GGT explicam-se pela absorção desta enzima por meio do colostro ingerido adequadamente, o qual possui um alto teor de GGT, já que bezerros sadios não possuem uma produção endógena tão elevada (BRAUN et al., 1978; BOYD, 1989; PERINO; SUTHERLAND; WOLLEN, 1993; FAGLIARI et al., 1996). Benesi et al. (2003) verificaram concentração máxima desta enzima entre 16 e 24 horas de idade (945 UI/L) e somente atingindo valores descritos para animais adultos aos 30 dias de idade $(24,00 \mathrm{UI} / \mathrm{L})$.

Tabela 2. Valores das enzimas hepáticas séricas de bezerros da raça Senepol, do nascimento até os 120 dias de idade.

\begin{tabular}{cccc}
\hline DIAS & $\begin{array}{c}\text { AST } \\
(\mathrm{U} / \mathrm{L})\end{array}$ & $\begin{array}{c}\text { GGT } \\
(\mathrm{U} / \mathrm{L})\end{array}$ & $\begin{array}{c}\text { FA } \\
(\mathrm{U} / \mathrm{L})\end{array}$ \\
\cline { 2 - 4 } $0-\mid 15$ & $71,10 \pm 14,86^{\mathrm{a}}$ & $112,0 \pm 179,6^{\mathrm{a}}$ & $265,6 \pm 151,7^{\mathrm{a}}$ \\
30 & $44,27 \pm 10,13^{\mathrm{b}}$ & $17,68 \pm 11,27^{\mathrm{b}}$ & $187,3 \pm 81,2^{\mathrm{ab}}$ \\
60 & $60,91 \pm 12,55^{\mathrm{a}}$ & $22,23 \pm 8,30^{\mathrm{b}}$ & $211,5 \pm 106,6^{\mathrm{ab}}$ \\
120 & $47,00 \pm 5,90^{\mathrm{b}}$ & $15,87 \pm 5,22^{\mathrm{b}}$ & $153,5 \pm 41,3^{\mathrm{b}}$ \\
Referência* & 78 a 132 & 6,1 a 17,4 & $0-488$ \\
\hline
\end{tabular}

* Kaneko, Harvey e Bruss (2008). Letras diferentes nas colunas diferem estatisticamente $(\mathrm{p}<0,05)$. AST- aspartato aminotransferase. GGT- gama-glutamil transferase. FA- Fosfatase Alcalina.

Fonte: Elaboração dos autores.

A concentração sérica de GGT em recémnascidos que ingeriram colostro pode ser de até 1000 vezes superior ao de animais adultos (LATIMER; MAHAFFEY; PRASSE, 2003). De acordo com Braun et al. (1982), os valores elevados de GGT nos primeiros 20 dias de vida de bezerros limita sua utilização para a avaliação funcional do fígado, particularmente em bezerros neonatos, que consumiram adequadamente o colostro nas primeiras horas de vida.

Neste estudo, a enzima GGT apresentou valores séricos superiores ao de referência (KANEKO; HARVEY; BRUSS, 2008) e de bezerros da raça Holandesa (FEITOSA et al., 2007), porém com resultados semelhantes aos bezerros de corte criados no Brasil, da raça Nelore, entre 14,04 $\pm 3,47$ e 41,56 
$\pm 21,90 \mathrm{U} / \mathrm{L}$, e da raça Limousin, entre 13,36 $\pm 3,48$ e $25,05 \pm 11,79 \mathrm{U} / \mathrm{L}$ no período entre 30 e 120 dias de vida (COSTA et al., 2008). Portanto, descarta-se a hipótese da hipoalbuminemia relacionada a uma hepatopatia (KANEKO; HARVEY; BRUSS, 2008).

O nível máximo de AST foi verificado no primeiro período e estava dentro da normalidade (Tabela 3). Essa alta concentração é bem descrita na literatura entre 16 e 24 horas pós-nascimento (BENESI et al., 2003; BOUDA et al., 1980;
BOYD, 1989; KURTZ; WILLET, 1991; MAACH; GRÜNDER; FAIO, 1991; FAGLIARI et al., 1996). Os valores encontrados na presente pesquisa para AST são superiores ao maior valor relatado por Benesi et al. (2003) de 27,50UI/L, entre 16 e 24 horas pós-nascimento, e Feitosa et al. (2007) de 36,9UI/L aos 120 dias; e não há consenso na literatura de correlação da ingestão de colostro e aumento de AST (BENESI et al., 2003; FEITOSA et al., 2007). Boyd (1989) correlacionou o aumento de AST ao aumento da atividade muscular.

Tabela 3. Valores dos constituintes do lipidograma sérico de bezerros da raça Senepol, do nascimento até os 120 dias de idade.

\begin{tabular}{ccccc}
\hline DIAS & $\begin{array}{c}\text { Triglicerí́deos } \\
(\mathrm{mg} / \mathrm{dL})\end{array}$ & $\begin{array}{c}\text { Colesterol } \\
(\mathrm{mg} / \mathrm{dL})\end{array}$ & $\begin{array}{c}\text { Uréia } \\
(\mathrm{mg} / \mathrm{dL})\end{array}$ & $\begin{array}{c}\text { Creatinina } \\
(\mathrm{mg} / \mathrm{dL})\end{array}$ \\
\cline { 2 - 5 } $0-\mid 15$ & $26,55 \pm 16,82^{\mathrm{ab}}$ & $79,44 \pm 23,16^{\mathrm{a}}$ & $24,61 \pm 6,83^{\mathrm{a}}$ & $1,61 \pm 0,60^{\mathrm{a}}$ \\
30 & $16,44 \pm 06,82^{\mathrm{a}}$ & $70,85 \pm 22,27^{\mathrm{a}}$ & $27,91 \pm 8,28^{\mathrm{a}}$ & $1,02 \pm 0,35^{\mathrm{b}}$ \\
60 & $31,45 \pm 10,06^{\mathrm{b}}$ & $70,25 \pm 20,73^{\mathrm{a}}$ & $23,04 \pm 13,20^{\mathrm{a}}$ & $0,98 \pm 0,20^{\mathrm{b}}$ \\
120 & $31,27 \pm 14,86^{\mathrm{b}}$ & $86,98 \pm 20,54^{\mathrm{a}}$ & $28,87 \pm 7,38^{\mathrm{a}}$ & $1,16 \pm 0,23^{\mathrm{b}}$ \\
Referência* & 0 a 14 & $80 \mathrm{a} 120$ & $20 \mathrm{a} 30$ & $1,0 \mathrm{a} 2,0$ \\
\hline
\end{tabular}

* Kaneko, Harvey e Bruss (2008). Letras diferentes nas colunas diferem estatisticamente $(\mathrm{p}<0,05)$. Relação A/G- relação albumina/ globulina.

Fonte: Elaboração dos autores.

Os valores da enzima FA diminuíram do nascimento até os 120 dias de idade (Tabela 2). Kramer e Hoffmann (1997) atribuíram os altos valores de FA em animais mais jovens devido à grande quantidade de isoenzimas ósseas da FA, liberadas em animais em crescimento e que pode ser três vezes maior do que em adultos. Moraes (2011) também observou o mesmo comportamento da FA, com valores chegando até $255,0 \pm 270,9 \mathrm{U} / \mathrm{L}$.

As concentrações séricas de triglicerídeos (Tabela 3) permaneceram acima dos valores de referência (KANEKO; HARVEY; BRUSS, 2008) que pode ter ocorrido pela ingestão de leite, por meio da mamada natural durante todo o experimento. Storry e Rook (1964) verificaram que os valores séricos de triglicerídeos dos bezerros não lactentes $(6,7 \pm$ $1,0 \mathrm{mg} / \mathrm{dL}$ ) eram menores do que os obtidos para os bezerros lactentes $(12,30 \pm 2,50 \mathrm{mg} / \mathrm{dL})$ devido à utilização de lipídios do leite.
Pogliani (2006) ao trabalhar com bezerros Holandeses no Estado de São Paulo, encontrou valores de $25,58 \pm 19,81 \mathrm{mg} / \mathrm{dl}$ e $27,93 \pm 9,76 \mathrm{mg} /$ dl, respectivamente, para bezerros com idade até 3 meses e de 3 a 6 meses, evidenciando significativa influência dos fatores etários nos valores dos triglicerídeos. Segundo o mesmo autor, durante o período de amamentação as concentrações de triglicerídeos oscilaram sem qualquer tendência a aumentar ou diminuir.

Os resultados encontrados para colesterol permaneceram no limite inferior de referência ou abaixo deste (KANEKO; HARVEY; BRUSS, 2008), e também dos relatados por Pogliani e Birgel Junior (2007) para bezerros Holandeses lactentes até 3 meses, entre 86,5 e $120,8 \mathrm{mg} / \mathrm{dl}$, e desmamados com 3 e 12 meses de idade, entre 46,3 e 79,7 mg/dl. Além disso, não houve alterações bruscas com o desenvolvimento etário, provavelmente, por serem animais lactentes, 
que se aproximando ao período da desmama, já se alimentavam de concentrado e pastagem, e não apresentaram situação de alimentação precária onde há necessidade de mobilização de reservas corporais (MORAIS et al., 2000).

De acordo com Associação Brasileira dos Criadores de Senepol (ABCBS, 2013), a ausência de gordura entremeada na carne decorre do baixo índice de colesterol existente em seu tecido muscular, o que pode caracterizar um menor nível de colesterol circulante peculiar da raça e que justificaria as baixas concentrações verificadas já nos bezerros. No entanto, não foi encontrado na literatura consultada valores de colesterol para esta raça, apenas a informação da espessura de gordura subcutânea de 4,8 mm no momento do abate, de animais previamente confinados por 90 dias (PEREIRA; SILVA, 2004).

Valores aumentados de uréia deveriam ter sido observados com o aumento da ingestão de concentrados, porém esta variação não foi percebida no delineamento proposto (Tabela 3). Jenkins, Green e Clark (1982) demonstraram a influência dos fatores etários sobre os valores séricos de ureia em bovinos, quando verificaram valores de ureia iguais a $25,7 \mathrm{mg} / \mathrm{dL}$ e $24,3 \mathrm{mg} / \mathrm{dL}$, respectivamente, em bezerros entre quatro a oito semanas e três a quatro meses de idade.
Os valores de creatinina mantiveram-se dentro dos limites estabelecidos por Latimer, Mahaffey e Prasse (2003) e de acordo com o encontrado por Moraes (2011), que atribuiu o aumento nos primeiros dias devido à imaturidade renal e ao desgaste muscular com o início da locomoção. Entretanto, esses resultados diferiram dos encontrados por Mendonça (2007), que relatou aumento significativo nos valores de creatinina devido ao crescimento dos animais, uma vez que o aumento de massa muscular afeta o pool de creatinina no soro de várias espécies animais (FINCON, 1997).

O comportamento inicial do cálcio (tabela 4) acompanhou a hipoalbuminemia instalada, o que concorda com González e Sheffer (2002), que citam que a hipoalbuminemia leva à diminuição de cálcio sérico. Aos 60 dias, o nível de cálcio normalizou juntamente com a albumina, podendo estar correlacionado com a maior ingestão de pastagem e concentrado na dieta (TOKARNIA et al., 2010). As concentrações de fósforo sérico (tabela 4) apresentaram a mesma tendência do cálcio e semelhante ao observado por Rocha et al. (2010) em bezerros Holandeses, filhos de mães pluríparas, do nascimento até os 30 dias de vida, porém diferente de bezerros mestiços CanchimNelore, neste mesmo experimento.

Tabela 4. Valores séricos dos minerais em bezerros da raça Senepol, do nascimento até os 120 dias de idade.

\begin{tabular}{ccccc}
\hline DIAS & $\begin{array}{c}\text { Cálcio } \\
(\mathrm{mg} / \mathrm{dL})\end{array}$ & $\begin{array}{c}\text { Fósforo } \\
(\mathrm{mg} / \mathrm{dL})\end{array}$ & Relação Ca/P & $\begin{array}{c}\text { Magnésio } \\
(\mathrm{mg} / \mathrm{dL})\end{array}$ \\
\cline { 2 - 5 } $0--\mid 15$ & $9,85 \pm 0,79^{\mathrm{a}}$ & $13,26 \pm 2,22^{\mathrm{a}}$ & $0,75 \pm 0,10^{\mathrm{a}}$ & $1,69 \pm 0,24^{\mathrm{a}}$ \\
30 & $7,30 \pm 0,76^{\mathrm{b}}$ & $7,26 \pm 1,08^{\mathrm{b}}$ & $1,00 \pm 0,13^{\mathrm{b}}$ & $1,28 \pm 0,20^{\mathrm{b}}$ \\
60 & $8,58 \pm 1,09^{\mathrm{c}}$ & $8,47 \pm 1,47^{\mathrm{c}}$ & $1,03 \pm 0,13^{\mathrm{b}}$ & $1,47 \pm 0,29^{\mathrm{ab}}$ \\
120 & $8,40 \pm 0,66^{\mathrm{c}}$ & $8,39 \pm 1,23^{\mathrm{bc}}$ & $1,01 \pm 0,14^{\mathrm{b}}$ & $2,11 \pm 0,39^{\mathrm{c}}$ \\
Referência * $^{*}$ & $8 \mathrm{a} 11,4$ & $5,6 \mathrm{a} 8$ & $2: 1$ & $1,5 \mathrm{a} 2,9$ \\
\hline
\end{tabular}

* Kaneko, Harvey e Bruss (2008). Letras diferentes nas colunas diferem estatisticamente (p < 0,05). Relação Ca/P- Relação cálcio/ fósforo.

Fonte: Elaboração dos autores. 
Apesar dos níveis de fósforo estar mais alto em animais jovens, devido ao hormônio do crescimento aumentar a absorção renal de fósforo (ROSOL; CAPEN, 1997), os maiores valores encontrados aos 15 dias de vida foram superiores ao descrito para bezerros Holandeses de 7,0 $\pm 2,1 \mathrm{mg} / \mathrm{dl}$ (MORAES, 2011) e 9,0 \pm 0,94 mg/dl (RIZZOLI et al., 2006).

As concentrações séricas de magnésio (tabela 4) encontraram-se abaixo dos valores de referência (LATIMER; MAHAFFEY; PRASSE, 2003) nos primeiros 60 dias de vida e observou-se a mesma dinâmica de queda dos outros minerais aos 30 dias e recuperação até os 120 dias de vida. Estes resultados discordaram de Fagliari et al. (1998) que não verificaram diferença significativa em bezerros da raça Nelore e de Rocha et al. (2010) em bezerros filhos de vacas pluríparas. Porém, verificaram queda semelhante ao de bezerros de vacas primíparas da raça Holandesa e mestiços Canchim-Nelore, mas dentro dos valores de normalidade.

Segundo Tokarnia et al. (2010), os valores mais baixos foram vistos nas idades lactentes, em que a exigência desse mineral é mais expressiva. A verdadeira deficiência de magnésio só ocorre em bezerros alimentados exclusivamente à base de leite, os chamados "bezerros de leite", já que o leite é pobre em magnésio e ferro.

Ressalta-se que na literatura nacional e internacional consultada não se encontraram trabalhos referentes à bioquímica em bovinos da raça Senepol. Os autores reforçam a importância do conhecimento destas informações na exploração dos benefícios da criação da raça Senepol e como fonte para banco de dados para futuros valores de referência.

Aos 30 dias de vida estes bezerros apresentaram valores baixos do proteinograma, minerais e triglicerídeos, normalizando aos 60 dias de vida, exceto para a albumina que apresentou recuperação mais lenta. Portanto, concluiu-se que há influência da faixa etária no comportamento dos constituintes bioquímicos analisados e há diferenças quando comparados a outras raças.

\section{Referências}

ASSOCIAÇÃO BRASILEIRA DE CRIADORES DE BOVINOS SENEPOL - ABCBS. Senepol - heterose garantida nos programas de cruzamento industrial a campo nos trópicos. 2013. Disponível em: <http:/http:// senepol.org.br/artigos/senepol-heterose-garantida-nosprogramas-de-cruzamento-industrial-a-campo-nostropicos/>. Acesso em: 19 ago. 2013.

BENESI, F. J. Síndrome asfixia neonatal dos bezerros: importância e avaliação crítica. Arquivos da Escola de Medicina Veterinária da Universidade Federal da Bahia, Salvador, v. 16, n. 1, p. 38-48, 1993.

BENESI, F. J.; LEAL, M. L.; LISBÔA, J. A. N.; COELHO, C. S.; MIRANDOLA, R. M. S. Parâmetros bioquímicos para avaliação da função hepática em bezerras sadias, da raça holandesa, no primeiro mês de vida. Ciência Rural, Santa Maria, v. 33, n. 2, p. 311-317, mar./abr. 2003.

BOUDA, J.; DVORAK, V.; MINKSOVÁ, E.; DVORAK, $\mathrm{R}$. The activities of got, gamma-gt, alkaline phosphatase in blood plasma of cows and their calves from fed buckets. Acta Veterinária Brno, República Tcheca, v. 49, n. 3-4, p. 193-198, jan. 1980.

BOYD, J. W. Serum enzyme changes in newborn calves fed colostrum. Veterinary Clinical Pathology, Madison, v. 18, n. 2, p. $47-51,1989$.

BRAUN, J. P.; TAINTURIER, D.; LAUGIER, C.; BÉNARD, P.; THOUVENOT, J. P.; RICO, A. G. Earl variations of blood plasma gama glutamyl transferase in newborn calves- A test of colostrum intake. Journal of Dairy Science, Savoy, v. 65, n. 11, p. 2178-2181, nov. 1982.

BRAUN, J.P.; RICO,A. G.; BENARD, P.; THOUVENOT, J. P.; BONNEFIS, M. J. Blood and tissue distribution of gamma glutamyltransferase in calves. Journal of Dairy Science, Savoy, v. 61, n. 5, p. 596-599, maio 1978.

CALDEIRA, R. M.; BELO, A. T.; SANTOS, C. C. The effect of long-term feed restriction and over-nutrition on body condition score, blood metabolites and hormonal profiles in ewes. Small Ruminant Research, Londres, v. 68, n. 3, p. 242-255, apr. 2007.

COLES, E. H. Patologia clínica veterinária. 3. ed. São Paulo: Manole, 1984. 566 p.

COSTA, M. C.; FLAIBAN, K. K. M. C.; CONEGLIAN, M. M.; FEITOSA, F. L. F.; BALARIN M. R. S.; LISBÔA, J. A. N. Transferência de imunidade passiva em bezerros das raças Nelore e Limousin e proteinograma sérico nos primeiros quatro meses de vida. Pesquisa Veterinária Brasileira, Rio de Janeiro, v. 28, n. 9, p. 410-416, set. 2008. 
EUCLIDES FILHO, K.; FIGUEIREDO, G. R.; EUCLIDES, V. P. B. Desempenho de diferentes grupos genéticos de bovino de corte em confinamento. Revista Brasileira de Zootecnia, Viçosa, v. 32, n. 5, p. 1114-1122, fev./mar. 2003.

EUCLIDES FILHO, K.; FIGUEIREDO, G. R.; EUCLIDES, V. P. B.; VAZ, E. C.; TROVO, J. B.; RAZOOK, A. G.; FIGUEIREDO, L. A.; SILVA, L. O. C.; ROCCO, V. Eficiência bionutricional de animais da raça Nelore, F1s Valdostana-Nelore. Arquivo Brasileiro de Medicina Veterinária e Zootecnia, Belo Horizonte, v. 56, n. 5, p. 671-675, out. 2004.

FAGLIARI, J. J.; OLIVEIRA, E. C.; PEGORER, M. F.; FERRANTE JÚNIOR, L. C.; CAMPOS FILHO, E. Relação entre o nível sérico de gamaglobulinas e as atividades de gamaglutamiltransferase, fosfatase alcalina e aspartato aminotransferase de bezerros recém-nascidos. Arquivo Brasileiro de Medicina Veterinária e Zootecnia, Belo Horizonte, v. 48, n. 2, p. 105-112, abr. 1996.

FAGLIARI, J. J.; SANTANA, A. E.; LUCAS, F. A.; CAMPOS FILHO, E.; CURI, P. R. Constituintes sanguíneos de bovinos recém-nascidos das raças Nelore (Bos indicus), e holandesa (Bos taurus) e de bubalinos (Bubalus bubalis) da raça Murrah. Arquivo Brasileiro de Medicina Veterinária e Zootecnia, Belo Horizonte, v. 50, n. 3, p. 253-262, jun. 1998.

FEITOSA, F. L. F. Semiologia veterinária: a arte do diagnóstico. 2. ed. São Paulo: Roca, 2008. 754 p.

FEITOSA, F. L. F.; MENDES, L. C. N.; PEIRÓ, J. R.; CADIOLI, F. A.; YANAKA, R.; BOVINO, F.; FÉRES, F. C.; PERRI, S. H. V. Influência da faixa etária em valores de enzimas hepáticas e de uréia e creatinina em bezerros holandeses do nascimento aos 365 dias de vida. Ciência Veterinária nos Trópicos, Recife, v. 10, n. 2-3, p. 54-61, dez. 2007.

FERREIRANETO, J. M.; VIANA, E. S.; MAGALHÃES, L. M. Patologia clínica veterinária. Belo Horizonte: Rabelo, 1982. 293 p.

FINCON, D. R. Kidney function. In: KANEKO, J. J.; HARVEY, J. W.; BRUSS, M. Clinical biochemistry of domestic animals. San Diego: Academic Press, 1997. cap. 17, p. 441-484.

GASPARELLI, E. R. F. Determinação da atividade sérica de enzimas hepáticas e da concentração de uréia, creatinina, cortisol e imunoglobulina $G$ e de valores hemogasométricos, de bezerros da raça Nelore oriundos de fertilização in vivo $(F V)$ e fertilização in vitro (FIV). 2007. Dissertação (Mestrado em Ciência Animal) - Faculdade de Odontologia e Curso de Medicina Veterinária. Universidade Estadual Paulista Júlio Mesquita Filho, Araçatuba.
GONZÁleZ, F. H. D.; SCHEFFER, J. F. S. Perfil sanguíneo: ferramenta de análise clínica, metabólica e nutricional. In: ARQUIVOS DO CONGRESSO NACIONAL DE MEDICINA VETERINÁRIA, 29., 2002, Gramado. Anais... Porto Alegre: UFRGS, 2002.

JENKINS, S. J.; GREEN, S. A.; CLARK, P. A. Clinical chemistry reference values of normal domestic animals in various age groups - AS determine don the ABA- 100 . The Cornell Veterinarian, Ithaca, v. 72, n. 4, p. 403-415, oct. 1982.

KANEKO, J. J.; HARVEY, J. W.; BRUSS, M. L. Clinical biochemistry of domestic animals. 6. ed. San Diego: Academic Press, 2008. 928 p.

KÖPPEN, W. Climatologia: con un estúdio de los climas de la Tierra. México: Fondo de Cultura Economica, 1948. $478 \mathrm{p}$.

KRAMER, J. W.; HOFFMANN, W. E. Clinical enzimology. In: KANEKO, J. J.; HARVEY, J. W.; BRUSS, M. L. Clinical biochemistry of domestic animals. 6. ed. San Diego: Academic Press, 1997. p. 303-325.

KURTZ, M. M.; WILETT, L. B. Carbohydrate, enzyme and hematology dynamics in newborn calves. Journal of Dairy Science, Savoy, v. 74, n. 7, p. 2109-2118, jul. 1991.

LATIMER, K. S.; MAHAFFEY, E. D.; PRASSE, K. W. Veterinary laboratory medicine: clinical pathology. 4. ed. Iowa: A Blackwell, 2003. 450 p.

LEAL, M. L.; BENESI, F. J. ; LISBÔA, J. A. N.; COELHO, C. S.; MIRANDOLA, R. M. S. Proteinograma de bezerras sadias, da raça holandesa, no primeiro mês pós- nascimento. Brasilian Journal of Veterinary Research and Animal Science, São Paulo, v. 48, n. 2, p. 138-145, out./dez. 2003.

MAACH, L.; GRÜNDER, H. D.; FAIO, A. Hämozytologische und hämobiochemische untersuchungen bei schwarzbunten, klinisch gesunden aufzuchtkälbern in marokko. Deutsche Tierärztliche Wochenschrift, Berlim, v. 98, n. 3, p. 94-102, mar. 1991.

MATTIOLI, R. C.; PANDEY, V. S. B.; MURRA, Y, M.; FITZPATRICK, J. L. Immunogenetic influences on tick resistance in African cattle with particular reference to trypanotolerant N'Dama (Bos taurus) and trypanosusceptible Gobra zebu (Bos indicus) cattle. Acta Tropica, Amsterdam, v. 75, n. 3, p. 263-277, 2000.

MENDONÇA, A. J. Avaliação hematológica, bioquímica e hemostática de bezerros Brahman provenientes de produção in vitro (PIV) e bezerros Brahman de produção in vivo. 2007. Tese (Doutorado em Ciências Veterinárias) - Faculdade de Medicina Veterinária e Zootecnia. Universidade Estadual Paulista, Botucatu. 
MORAES, D. V. Perfil bioquímico sérico de bezerros mestiços duranteo primeiro ano de vida.2011. Dissertação (Mestrado em Ciências Veterinárias) - Faculdade de Medicina Veterinária e Zootecnia. Universidade Federal de Uberlândia, Uberlândia.

MORAIS, M. G.; RANGEL, J. M.; MADUREIRA, J. S.; SILVEIRA, A. C. Variação sazonal da bioquímica clínica de vacas aneloradas sob pastejo contínuo de Brachiaria decumbens. Arquivo Brasileiro de Medicina Veterinária e Zootecnia, Belo Horizonte, v. 52, n. 2, p. 94-104, abr. 2000.

MUNDIM, A.V.; COSTA, A. S.; MUNDIM, S. A. P.; GUIMARÃES, E. C.; ESPINDOLA, F. S. Influência da ordem e estádios da lactação no perfil bioquímico sangüíneo de cabras da raça Saanen. Arquivo Brasileiro de Medicina Veterinária e Zootecnia, Belo Horizonte, v. 59, n. 2, p. 306-312, abr. 2007.

OLSON, T. A.; LUCENA, C.; CHASE JUNIOR, C. C.; HAMMOND, A. C. Evidence of a major gene influencing hair length and heat tolerante in Bos taurus cattle. Journal of Animal Science, Champaign, v. 81, n. 1, p. 80-90, 2003.

PAULETTI, P.; MACHADO NETO, R.; PACKER, I. U.; D'ARCE, R. D.; BESSI, R. Quality of colostral passive immunity and pattern of serum protein fluctuation in newborn calves. Scientia Agricola, Piracicaba, v. 60, n. 3, p. 453-456, 2003.

PAYNE, J. M.; PAYNE, S. The metabolic profile test. Oxford: Oxford University Press, 1987. 179 p.

PEIXOTO, L. A. O.; OSÓRIO, M. T. M.; OSÓRIO, J. C. S.; NORNBERG, J. L; PAZINI, M. Metabólitos sanguíneos de ovelhas Ile de France sob suplementação com sal orgânico ou sal comum durante a estação de monta. Revista Brasileira de Zootecnia, Viçosa, v. 39, n. 1, p. 191-197, 2010.

PEREIRA, A. S. C.; SILVA, S. L. Avaliação das características de carcaça e da qualidade de carne de novilhos Senepol. [S.1.: s.n], 2004. (Relatório técnico). Disponível em: <http://senepol.org.br/liq/upload/ conteudo_editor/File/AbateTecnico2004.pdf>. Acesso em: 19 set.2012.

PERINO, L. J.; SUTHERLAND, R. L.; WOLLEN, N. E. Serum gammaglutamyltransferase activity and protein concentration at birth and after suckling in calves with adequate and inadequate passive transfer immunoglobulin G. American Journal of Veterinary Research, Chicago, v. 54, n. 1, p. 56-59, jan. 1993.

PIKE, R. M. Antibody heterogeneity and serologic reactions. Bacteriol. Reviews, Washington, v. 31, n. 2, p. 157-174, jun. 1967.
POGLIANI, F. C. Valores de referência e influência dos fatores etários, sexuais e da gestação no lipidograma de bovinos da raça Holandesa, criados no Estado de São Paulo. 2006. Dissertação (Mestrado em Clínica Veterinária) - Faculdade de Medicina Veterinária e Zootecnia. Universidade de São Paulo, São Paulo.

POGLIANI, F. C.; BIRGEL JUNIOR, E. H. Valores de referência do lipidograma de bovinos da raça Holandesa, criados no Estado de São Paulo. Brazilian Journal of Veterinary Research Animal Science, São Paulo, v. 44, n. 5, p. 373-383, 2007.

RIBEIRO, A. R. B.; ALENCAR, M. M.; OLIVEIRA, M. C. S. Características do pelame de bovinos Nelore, Angus x Nelore e Senepol x Nelore. In: REUNIÃO ANUAL DA SOCIEDADE BRASILEIRA DE ZOOTECNIA, 45., 2008, Lavras.... Anais... Lavras: Editora, 2008. p. 1-3.

RIZZOLI, F. W. ; FAGLIARI, J. J. ; SILVA D. G.; SILVA, S. L.; JORGE, R. L. N. Proteinograma e teores séricos de cálcio, fósforo, magnésio e ferro de bezerros recémnascidos que mamaram colostro diretamente na vaca ou em mamadeira. ARS Veterinária, Jaboticabal, v. 22, n. 3 , p. 198-202, abr. 2006.

ROCHA, T. G.; FRANCIOSI, R. P.; NOCITI, C. A. S.; NOGUEIRA, J. J.; FAGLIARI, J. J. Hemograma e proteínas do soro sanguíneo de bezerros Canchim-Nelore e da raça Holandesa nos primeiros 30 dias de vida. Arquivo Brasileiro de Medicina Veterinária e Zootecnia, Belo Horizonte, v. 62, n. 5, p. 1250-1254, set. 2010.

ROSOL, T. J.; CAPEN, C. C. Calcium-regulating hormones and diseases of abnormal mineral (calcium, phosphorus, magnesium) metabolism. In: KANEKO, J. J. (Ed.). Clinical biochemistry of domestics animals. 5. ed. New York: Academic Press, 1997. p. 619-702.

SRIDHAR, S. P. P.; KUMAR, R. Hemato-biochimical changes in calves during neonatal life. Indian Journal Animal Health, Caucutá, v. 27, n. 2, p. 105-109, 1988.

STORRY, J. E.; ROOK, J. A. Lipids in the blood plasma of cows of the friesian and channel island breeds. Nature, Londres, v. 29, n. 201, p. 926, fev. 1964.

TOKARNIA, C. M. H.; PEIXOTO, P. V.; BARBOSA, J. D.; BRITO, M. F.; DÖBEREINER, J. Deficiências minerais em animais de produção. Rio de Janeiro: Editora Helianthus, 2010. 191 p.

VIEIRA, S. Bioestatística: tópicos avançados. Rio de Janeiro: Elsevier, 2003. 216 p. 